\title{
VIRTUAL REALITY TRAINING FOR AVIATION MAINTENANCE, REPAIR AND OVERHAUL (VI-MRO 1.0)
}

\author{
Joke Van Vooren, VIVES University of Applied Sciences, Belgium
}

\section{MRO aviation is struggling}

The economic crisis of 2008-2013 had a huge impact on the industry and this was no different within aviation. During this period the number of recruitments within the industry was kept on a bare minimum, resulting in an ageing workforce today. According to the Q4 2017 Educavia survey on the employment by age and sector over $46 \%$ of the staff in the Aviation Maintenance, Repair and Overhaul (MRO) sector in Belgium and the Netherlands is over 50 years old. The sector indicates to be looking for extra and "younger" aviation mechanics to guarantee the continuity of the sector, but is announcing at the same time that there simply aren't enough suitable candidates.

In the meanwhile, the future within aviation is looking brighter. The European aviation industry is expected to grow by $5 \%$ a year. As a result, more and newer aircraft are being put into service. This next generation of aircrafts are quieter, have the latest technologies on board, are made of lightweight materials and emit less $\mathrm{CO}_{2}$ than other units of the same size. The introduction of these innovative technologies changes the landscape for aviation mechanics and the nature of their job.

Consequently, the MRO sector is sounding the alarm as they aren't able to optimise their workforce, not in number not in knowledge and experience in terms of approaching innovative technologies.

To make matters worse, the fierce competition within the aviation industry to keep flying affordable puts the operational costs under constant pressure. As the Maintenance, Repair and Overhaul (MRO) usually amounts to $10-15 \%$ of the operational costs, the MRO sector is constantly looking for new opportunities to be more time- and cost-efficient, in addition to existing challenges.

The solution for this wide range of challenges within the MRO sector lies in the application of virtual technology.

\section{Virtual Reality Training as a solution}

The use of Virtual Reality (VR) as a training tool is well known and various studies have already shown its added value in numerous areas. This has not gone unnoticed within the aviation industry. 


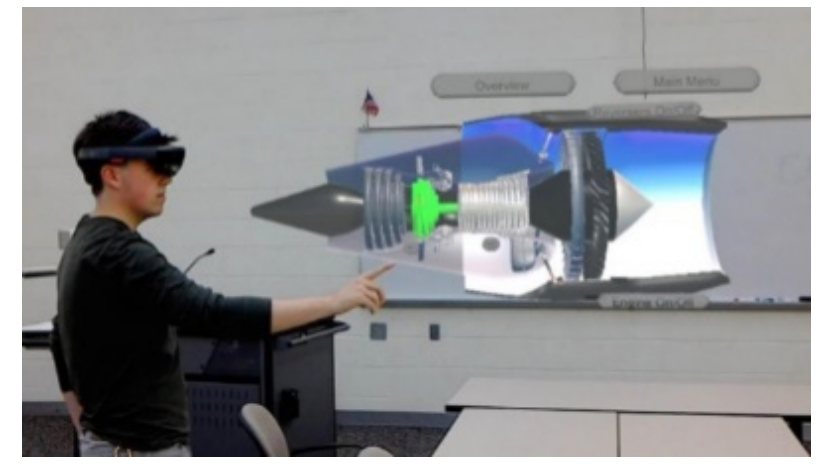

Figure 1.

Various aircraft manufacturers and world-class airlines have started test projects and, based on the results, have introduced VR within their organisation to improve training efficiency, reduce risks, speed up maintenance processes, etc.

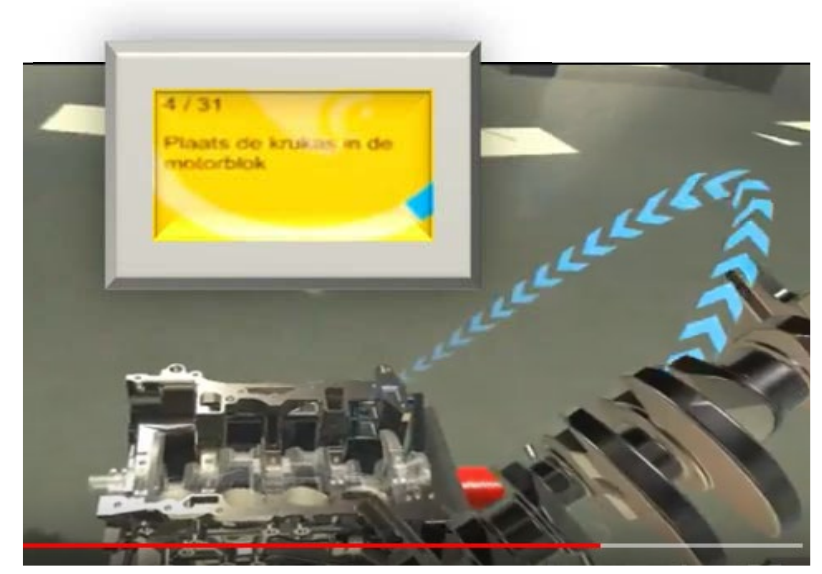

Figure 2.

Boeing, for example, is of the opinion that VR training reduces training time by $75 \%$ per person by literally getting to grips with the procedure, thanks to the so-called learning by doing principle.

VR training benefits for Aviation Maintenance Repair and Overhaul (MRO) in specific:

- Increase in effectiveness. The key selling point of VR training is its ability to create highly immersive environments. Greater immersion increases the retention rate and since the trainees can practice their skills as many times as needed, the knowledge becomes part of their muscle memory too.

- Elimination of risk for people and material. As novices are the most likely to make mistakes, they need a safe place to practice their skills until they are confident in them and VR training provides just that. This way the unexperienced aviation mechanic can't lose his/her fingers, but also the 8-million-euro aircraft engine can't get damaged.

- Endless repeatability. Trainees can repeat exercises as often as required or desired. This way the "young" aircraft mechanic can get to grips with the procedure. But also the 
more experienced aircraft mechanic can refresh the specific procedure before having to perform it in real-life under time pressure.

- Increased flexibility. VR training is an on-the-job-training for which the aircraft does not even be on the ground. In this way, trainees can already gain knowledge and experience with new technologies that - as a matter of speak - are still on the drawing board.

- More affordable training. Official multi-day MRO training courses in official training centres abroad go hand in hand with a considerable loss in time and money. Also the in-house on-the-job-training requires large modular spaces for large and expensive equipment, needing constant renewal. Taking all this in consideration, makes VR training very affordable.

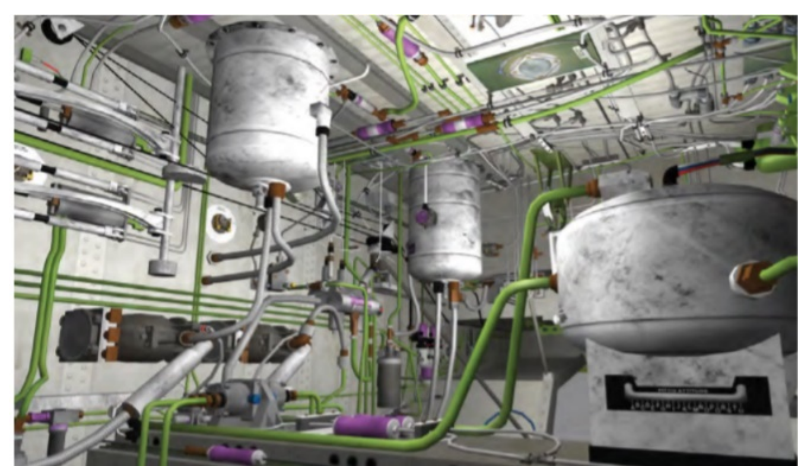

Figure 3.

These are a few of the features that make VR training so much better than regular old instructional based training. As the technology evolves, more immersive training solutions will emerge allowing people to train faster, better and cheaper than ever before.

Despite the fact that many aviation companies have put VR training into use, experienced and confirmed the benefits of it, none of them offers it to their customers.

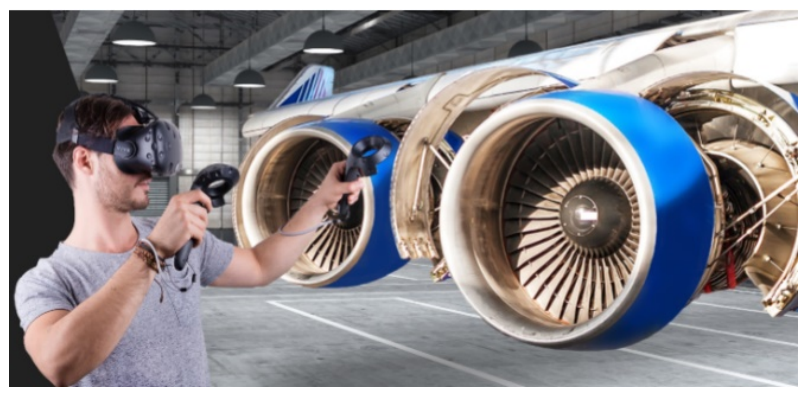

Figure 4.

In response to the needs within the Flemish-Dutch MRO sector, the research group Aviation of VIVES campus VLOC in Ostend has taken up the challenge and started this Vi-MRO project within the Interregions project Educavia. Together with potential end-users, MRO companies within the Educavia project group, bachelor students, VR and aviation experts the optimal VR MRO training will be developed. 


\section{Virtual Reality Training: Set-up}

In order to result in an effective VR MRO training the most immersive implementation of virtual reality technology is needed. In such a fully-immersive simulation, hardware such as head-mounted displays and motion detecting devices are used to stimulate all of a trainees' senses. As only if it looks real and feels real, the human brain accepts the artificial, virtual environment as real.

Next to this it should be created to maximize intuitiveness as this VR MRO training will be used as on-the-job training tool for young inexperienced aviation mechanics but also for older aviation mechanics needing additional training. This was achieved by the construction of the different modules and the realisation of each module separately, as explained below.

\section{Onboarding tutorial}

The story of dealing with an innovative VR training starts from the first impression through the decision on trying and up to the actual interaction. All this process usually takes a little time but it's often crucial to set the bonds between the user and the product.

This onboarding tutorial is the first interaction with the product, the first module of the VR MRO training. It is created to smoothen the transition of the trainee from the real into the virtual world. It will help newcomers to adapt to the new environment and the use of its controllers. It is crucial that the unboarding tutorial is fun and easy to understand, so that trainees are well-informed but more importantly also triggered and interested in what is yet to come.

\section{Tutorial}

The creation of the tutorial and testing module starts with the selection of the most suitable MRO task. On the one hand, the selected MRO task must be suitable for a development in VR. On the other hand, this task must be an answer to the existing needs within the sector.

The selected maintenance task is specified to its smallest detail and translated into a VR MRO training.

In the tutorial module the level of interactivity of the trainee is kept at a minimum to allow the trainee to get acquainted with the new environment and grow into the new experience. It is crucial that even in this tutorial module, the training approaches reality as closely as possible with attention to the importance of intuitiveness. Therefore, at each step the work card with the relevant part of the procedure must remain visible while every detail is explained and demonstrated. It is also essential to emphasise the signing off of the work card after each well executed intermediate step.

\section{Testing module}

The testing module is the heart of the VR MRO training. Through immersive VR scenes and extensive interactivity, the human senses reach a sufficient belief that the digital environment 
is real. As of that moment the trainee will be able to interact with the environment in a natural, intuitive manner and feel part of the simulated "universe".

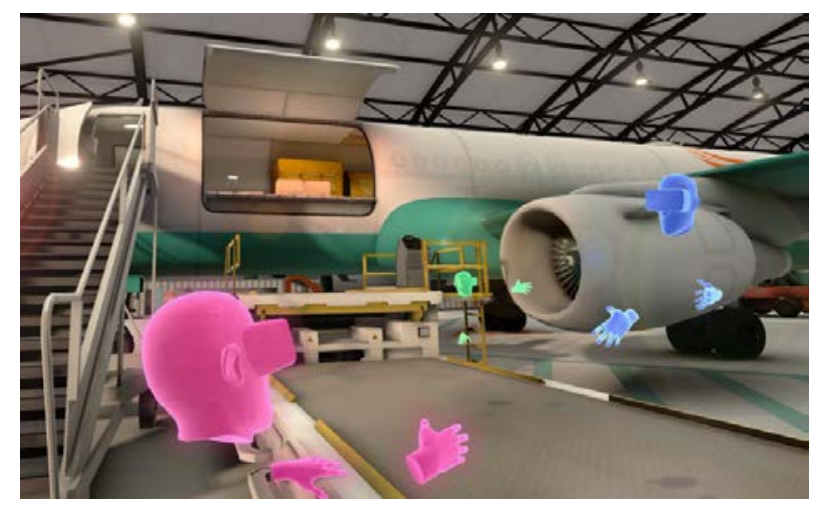

Figure 5.

In the testing module interactivity is key. Based upon the previous 2 modules the trainee can now demonstrate his/her knowledge of each step of the working procedure. Again it is important that the work card with the relevant part of the procedure remains visualized, as in real-life. Each step must be carried out completely and correctly by the trainee. After execution, the trainee should also have the reflex to sign off the finished part of the task.

Along the way, each action is evaluated by the system. Each mistake is identified and the correct way of working is demonstrated so that the trainee can repeat his/her action and learn from it.

\section{Archive}

In order for the trainer to get an overview of overall and individual training results a wide range of training parameters will be archived, such as trainee data, number of training sessions, time needed, problems etc. These data will also be used to evaluate possible issues within the VR MRO training.

\section{Virtual Reality Training: Optimization}

A differentiated test panel of potential end users - namely Flemish, Dutch, young, older aircraft mechanics with different knowledge levels - will be selected amongst the partner MRO companies and VIVES aviation bachelor students. These potential end-users will participate in test trainings to evaluate the (interim) result from concept to end product. Based on their iterative feedback, possible product modifications will be investigated to achieve the most optimal VR MRO training for the end user.

\section{Continuation}

The technological and operational knowledge developed will be included in the curriculum of VIVES Aviation Bachelor in the field of Industrial Sciences and Technology. This will give the course "MRO Aircraft Maintenance" more practical added value through the availability of digital tools. This is an important preparation for the moment that EASA, the European regulator, allows VR/AR as a recognised training tool. 
The Vi-MRO project will be completed by the end of the 2018-2019 academic year, so intermediate and final results shall be available at the $28^{\text {th }}$ Eden Conference in Bruges 16-19 June 2019.

\section{References}

Airbus' Training (Oct 2017). Maintenance Training - Reaching new horizons together

Boeing (n.d.). Introducing the 737 MAX 10. Retrieved from http://www.boeing.com/commercial/737max10/index.page\#/videos/employees-usevirtual-reality-for-737-max-10-preparations

Educavia (n.d.). https://educavia.eu/about-educavia

European Commission (2012). Transport: New horizons for EU aviation. Retrieved from http://europa.eu/rapid/press-release_IP-12-1027_en.htm

Farra, S., Miller, E., Timm, N., \& Schafer, J. (2013). Improved training for disasters using 3-D virtual reality simulation. Western Journal of Nursing Research, 35(5), 655-671.

Houtkamp, J. M., \& Bos, F.A. (2007). Evaluation of a virtual scenario training for leading firefighters. Proceedings of the $4^{\text {th }}$ International ISCRAM Conference, 565-570. Delft, the Netherlands.

IATA's Maintenance Cost Task Force (Nov 2018). IATA Airline Maintenance Cost Executive commentary. Chapter 1.3

Kishore, A. (2017, June 6). Boeing: Productive VR Cuts Training Time by 75\%. LightReading [Blog post]. Retrieved from https://www.lightreading.com/video/video-services/boeingproductive-vr-cuts-training-time-by-75-/d/d-id/733756

Reality (n.d.). The Ultimate Guide to Understanding Virtual Reality (VR) Technology. Retrieved from https:/www.realitytechnologies.com/virtual-reality/ 